\title{
Contra censura e indenizações, nova regulamentação para mídia
}

\author{
Mayra Rodrigues Gomes, Ivan Paganotti e Nara Lya Cabral
}

\section{Resumo:}

Entrevista com Prof. Dr. Sérgio Mattos, autor de livros referenciais como Mídia controlada, Censura de guerra: da Criméia ao Golfo Pérsico e O controle dos meios de comunicação. Mattos aponta que é função do Estado melhorar o arcabouço legal sobre os direitos, limites e deveres da mídia: "Quando há uma pressão da mídia num caso específico pela autorregulamentação, e o governo aceita, ele está se omitindo", expõe.

\section{Palavras Chave:}

Censura, liberdade de expressão, liberdade de imprensa.

\begin{abstract}
:
Interview with Prof. Sérgio Mattos, author of essential books such as Media under control, War censorship: from the Crimea to the Persian Gulf and The control of the media. Mattos points out that it is the State's role to improve the legal rights, limits and duties of the media: "When there's pressure from the media in a specific case, asking for space to build its own law by itself, if the government accept it, the State is neglecting its function", he says.
\end{abstract}

\section{Keywords:}

Censorship, free speech, free press.

Ao encarar os erros e abusos cada vez mais evidentes dos veículos informativos, a sociedade tem exigido o controle de meios de comunicação. Muitos advogados e juristas viram nessas demandas sociais uma justificativa para construir uma verdadeira indústria que sufoca empresas jornalísticas com pesadas indenizações. A saída, como sugerido por Sérgio Mattos, pode ser um remédio amargo, que os próprios jornais relutam em engolir: maior regulamentação do setor de comunicações no Brasil. Entretanto, se não forem transformados, os atuais cortes cirúrgicos - sejam financeiros, por meio das pesadas indenizações, ou de censura, devido a processos judiciais calcados nas brechas do código civil - podem levar a uma sangria letal de muitos órgãos da imprensa. 
Na entrevista, cedida após sua palestra proferida no Seminário Comunicação e Cultura, realizado em agosto, na ECA-USP, Mattos aponta que é função do Estado melhorar o arcabouço legal sobre os direitos, limites e deveres da mídia: "quando há uma pressão da mídia num caso específico pela autorregulamentação, e o governo aceita, ele está se omitindo", expõe.

Mattos pesquisa há quase trinta anos a influência econômica e política no controle dos meios de comunicação, tendo publicado trabalhos referenciais como Mídia controlada (1), Censura de guerra: da Criméia ao Golfo Pérsico (2) e O controle dos meios de comunicação (3). Na entrevista a seguir, Mattos reflete sobre o maior cerceamento judicial da liberdade de imprensa e aponta uma possível retaliação jurídica em reação à cobertura jornalística de escândalos no judiciário.

(Mayra Rodrigues Gomes) Em 1988 foi abolida a lei da censura prévia e, depois disso, o tempo inteiro se conversa sobre a censura - como você mencionou hoje [no Seminário Comunicação \& Censura] - como possível contenção dos meios de comunicação. Mas eu acho que nós estamos com outro tipo de processo censório, que tem o mesmo peso da censura antiga, só que ele opera em nível Judiciário. Essa linha fina, limítrofe, entre a liberdade de expressão, o direito à informação e o direito à privacidade, penso que veio para ficar - a menos que tenhamos, nunca se sabe, regimes autoritários pela frente. Como você vê esse processo que, depois de 2000, ficou bastante notório?

(Sérgio Mattos) Nós tivemos um momento em que a Lei de Imprensa ficou meio suspensa, não estava sendo aplicada, até que foi cassada. Mas já se discutia que a Lei de Imprensa iria cair, era um mecanismo do regime militar que não deveria ser aplicado. E isso levou juristas e advogados a descobrirem brechas no código civil e no código penal, que permitem a aplicação de ações de censura. Ao descobrirem essas brechas, eles perceberam também as possibilidades de se exigir indenizações e é exatamente, a partir daí que os jornais passaram a combater a indústria da indenização, ou seja, a "indústria do dano moral". Então, mesmo sem ser adepto da futurologia, pode-se prever que uma nova lei específica vai ter que surgir. Precisamos de um novo marco regulatório para a mídia. É o que se está querendo, uma lei geral das comunicações ou uma nova lei de imprensa específica. Existe uma parte dos juristas que acredita que não há necessidade, porque o código civil cobre tudo isso. Mas quanto à indenização, precisaria ter uma [lei] específica, porque o caso já é diferente. Então, eu acho difícil que essa situação permaneça sem uma lei específica e possivelmente essa questão pode ser contemplada na lei geral de comunicações, que está sendo adiada, mas é do interesse dos órgãos de imprensa - todos eles têm interesse em limitar os abusos que estão sendo praticados na aplicação de indenizações. Isso porque qualquer juiz pode decretar um valor arbitrário que pode contribuir para a falência de empresas jornalísticas, sem condições de pagar as indenizações. O jornal A Tarde, por exemplo, já teve períodos de ter dezenas de processos por ano. Em 2008 só a Igreja Universal entrou com 35 ações contra o jornal e contra um de seus repórteres, o jornalista Valmar Hupsel. Isso na Bahia. E aqui em São Paulo, quantos processos são movidos contra O Estado de S. Paulo e a Folha de S. Paulo por mês? Acredito que uma quantidade bem maior do que contra jornais do Nordeste. Qualquer pessoa hoje pode entrar com processos de qualquer natureza contra um jornal. Lá na Bahia, um fotógrafo ganhou 150 mil reais em uma questão na Justiça porque o jornal publicou uma foto sem dar o crédito de que a fotografia era dele. E o jornal, além de pagar a indenização, ainda foi obrigado a publicar a mesma fotografia, três dias seguidos, dizendo "essa foto pertence a fulano de tal...". Não estamos aqui discutindo os direitos autorais desse caso específico, mas o desequilíbrio, ou melhor, o abuso, na atribuição de valores exorbitantes nos casos de ações judiciais contra a mídia, que podem intimidar jornalistas e empresas, levando-os à prática da autocensura. O que não podemos aceitar, sem protestar, é a postura adotada pelo Judiciário, que tem se arvorado como árbitro da liberdade de imprensa e por meio de liminares vem amordaçando a mídia e intimidando os profissionais.

(Mayra Rodrigues Gomes) Então, na realidade, você vê um sentido muito pragmático para a lei, porque ela iria, de certa forma, dar um direcionamento, um norte, para quando se entra em ações judiciais. Mas sempre temo que, nesse pacote com um norte para ações, nós tenhamos um 
cerceamento maior da liberdade de expressão como um todo. Você deve estar ciente de que o grande argumento, até no meio jornalístico, para negar a necessidade do diploma de Jornalismo é justamente que sua necessidade seria uma infração à liberdade de expressão.

(Sérgio Mattos) No caso do diploma, acho que houve um erro de julgamento entre liberdade de expressão e liberdade de informação. O Supremo, além de confundir liberdade de expressão com exercício profissional, argumentou que o diploma impede a liberdade de expressão e isto é um erro grosseiro. E isso é o que espanta a todo mundo da área: como é que Gilmar Mendes, ministro do Supremo, não percebe a diferença entre uma coisa e outra? Eu não acredito que ele não saiba. Ele sabe. $\mathrm{Na}$ verdade, quero crer, foram as pressões que o próprio Supremo vinha sofrendo por parte dos proprietários dos veículos, que tinham um interesse em derrubar a exigência do diploma, isso não é uma coisa nova. Historicamente, o movimento contrário a exigência do diploma existe desde o período de criação das primeiras escolas de Jornalismo, nas décadas de 1940 e 1950 . O primeiro projeto de curso de Jornalismo foi pensado por Anísio Teixeira, em 1937, durante o Estado Novo. Posteriormente, em 1947, foi criada a Escola de Jornalismo Cásper Líbero. Desde a implantação das escolas de jornalismo que o diploma sofre uma campanha contrária promovida principalmente pelos donos de jornais. Porque eles achavam que os salários seriam aviltados. Havia o medo de que o jornalista profissional viesse a causar [prejuízo] aos que já estavam em exercício e começassem a ser vinculados a sindicatos. Mas, com as escolas, o jornalismo evoluiu. Jornalismo naquela época (década de 1950, até meados de 1970) era um grande bico para todas as profissões. Todo mundo que queria se destacar em alguma profissão - médico, advogado, entre outras - era jornalista também, porque tinha como se projetar. Os profissionais de outras áreas, que atuavam como jornalistas, além de ter visibilidade social, principalmente na década de 1950, tinham privilégios fantásticos. Para você ser jornalista bastava ser amigo do dono do jornal, para ganhar uma carteirinha através da qual, com a simples apresentação da mesma, o individuo passava a ter uma série de isenções, inclusive, em imposto de renda. Entre as vantagens estavam desconto de 50\% no preço de passagens aéreas, não pagar entrada de cinema, etc. Jornalista, na época tinha desconto em tudo. Quando veio o golpe militar, em 1964, e a profissão foi reconhecida e o diploma de nível superior exigido, as benesses acabaram. E o reconhecimento da profissão, embora tenha ocorrido durante o regime militar, contribuiu, gostem ou não, para melhorar a qualidade do jornalismo, que passou a ter ética e técnica. A luta contra o diploma vem desde essa época. Ele nunca foi aceito pelos donos dos jornais, e eles também nunca respeitaram a legislação. Quando eles queriam colocar algum funcionário que não era jornalista diplomado, eles simplesmente contratavam e ficava por isso mesmo, não adiantava o Sindicato espernear. Um dono de uma emissora de televisão, lá da Bahia, por exemplo, viajou e achou uma aeromoça bonita e convidou-a para ser repórter, foi o suficiente para a moça começar a trabalhar em televisão.

Na verdade, o jornalismo está sofrendo uma retaliação. Tanto por parte dos políticos, todos que apanharam da imprensa, como também por parte dos juízes. Antes da cassação do diploma, por exemplo, a imprensa nacional denunciou escândalos na construção de tribunais e os desembargadores envolvidos conseguiram liminares para proibir a imprensa de divulgar os escândalos. Então, diante de tantos casos específicos, só podemos imaginar, ou melhor, concluir, que algumas atitudes foram e são tomadas como retaliação. Esta é uma questão que eu gostaria de levantar: pesquisar a relação dos ministros do Supremo com a imprensa ao longo de suas respectivas carreiras, para a gente ver até que ponto eles sofreram com a imprensa ou não.

(Ivan Paganotti) E mesmo que um juiz nunca tenha pessoalmente sofrido um processo como esse também não exclui a possibilidade de ter ocorrido com seus colegas...

(Sérgio Mattos) Não exclui, até porque todas as vezes que o governo faz alguma coisa que não dá certo, a culpa é da imprensa. O político perde uma eleição, a culpa é da imprensa. Tudo é culpa nossa. A imprensa passou a ser responsável por tudo, apesar do jornalismo não ser responsável por desvio de verbas e outras práticas corruptas. E tem outra coisa: dizer que a exigência do diploma foi eliminada por se tratar de um resquício da ditadura é uma balela... Então, por que não cassaram também os diplomas dos 
médicos e dos advogados? Porque os rábulas e as parteiras foram proibidos de atuar exatamente nesse período. As profissões foram reconhecidas nessa mesma fase, pelo mesmo governo. Por que o argumento de que o diploma é resquício do regime militar só vale para o jornalismo?

(Ivan Paganotti) E a dificuldade de colocar em uma balança o direito coletivo (como o direito à informação) que às vezes se contrapõe ao direito individual, que é o da privacidade, o direito à imagem? Se um meio de comunicação diz que tal pessoa é um criminoso e não era, depois se dá uma indenização; a reputação dessa pessoa morreu, a vida dele acabou...

(Sérgio Mattos) Este é o outro lado da moeda, onde reside a culpa da imprensa e devemos assumir o "mea culpa". A maioria dos casos citados, exemplos dos erros da mídia, esbarram na falta de checagem das informações por parte da imprensa, por parte dos jornalistas, que na pressa e no desejo de antecipar os fatos, acabam divulgando-os antes que eles venham a ser realmente checados. Quer dizer, a imprensa não foi correta. Quando o jornalista divulga que o cara é culpado sem ele ter sido julgado, então, a culpa é nossa. Se você publica a fotografia de um cara e diz que ele é um assassino, e o cara não é, ele é inocente... Então, de quem que é a culpa? Da imprensa. Então, está faltando o quê? Um pouco mais de ética e profissionalismo. Nós estamos vivendo um momento em que o jornalismo está sendo praticado sem levar em conta, com o rigor necessário, os princípios e conceitos éticos. A quantidade de erros éticos ou desvios éticos que são cometidos pela imprensa brasileira, diariamente, era para termos vários processos todos os dias.

\section{(Ivan Paganotti) Por isso que tem inúmeros processos por mês.}

(Sérgio Mattos) E aí, quando há negligência profissional, é óbvio, o erro é nosso. Eu acho que, para corrigir a situação, é preciso evitar as falhas na apuração e na produção de conteúdos, é necessário checar os dados antes de divulgá-los. E aí, como alguns podem alegar, não se trata de uma situação de censura prévia ou de autocensura, mas de profissionalismo. Quais são os princípios jornalísticos que não estão sendo cumpridos? Nesses casos, quando os erros são cometidos pela imprensa, ela é julgada pela opinião pública, e isso não é censura, não é abuso do poder judiciário. $\mathrm{O}$ erro é nosso e temos que bater no peito e dizer "é minha culpa". Quer dizer, a imprensa passou a se omitir frente a determinadas situações e a cometer excessos em outras. É difícil hoje você conversar com estudantes de Jornalismo porque o pessoal não está mais calcado nos princípios, eles querem pegar qualquer denuncia e divulgar sem checar a veracidade dos fatos e a credibilidade das fontes. Talvez seja a influência da internet: onde as pessoas pegam qualquer coisa e depois colocam no ar, disponibilizam qualquer informação sem responsabilidade nenhuma? Onde está a responsabilidade social do jornalista e do veículo? Dos chefes de reportagem, do editor que deixou passar e não verificou, não mandou checar aquela informação? Não adianta apenas assumir e publicar "nós erramos"... Ao divulgar notícias não verificadas o jornalista pode matar pessoas, destruir a vida de empresas, e depois de tudo diz "nós erramos". Você se justificou por isso? Cheque as informações antes de divulgá-las. Temos que fazer uma revisão completa dos nossos princípios, das posições éticas, não apenas do profissional, mas também das empresas, para praticarmos um jornalismo de qualidade. E isso é o que vai diferenciar o jornalista profissional do "repórter cidadão", do "jornalista cidadão", e de todos aqueles que querem exercer o jornalismo como "bico" e não como uma profissão, que exige capacitação de nível universitário, onde a ética deve ser debatida transversalmente, por todas as disciplinas, durante todo o curso.

(Ivan Paganotti) O Zuenir Ventura diz que antes mal se podia falar sobre a censura e agora pelo menos há uma discussão nos tribunais, essa questão é amparada, você tem o espaço de recorrer e antes era o "não" e pronto. Em seu próprio livro, no "Mídia Controlada" (4), o senhor chega a mencionar que um dos problemas mais graves não era o episódico corte de uma palavra, de uma imagem, de um tema, de uma cena, mas a própria estrutura censória, em que um autor aceitava submeter o seu trabalho sistematicamente a alguém que desse a chancela de aprovação. Pelo menos hoje não há mais essa estrutura de sujeição prévia. Ela é episódica, no Brasil, nos 
grandes centros, na situação que a gente enfrenta hoje. Isso ainda assim diminuiria o problema da censura como um todo ou é talvez uma questão pior ainda: por estar em um Estado de direito, ainda assim há essa regra, essa exceção?

(Sérgio Mattos) Eu acho que a tendência é aumentar o número de casos. O problema maior é a conscientização da população e dos leitores envolvidos no processo, que descobriram e se conscientizaram dos erros da imprensa, então eles estão entrando na Justiça para serem indenizados. Estamos pagando um preço também pelo próprio alargamento da comunicação. A televisão hoje cobre quase $100 \%$ do país, a internet já pega uma quantidade de acesso grande, celular todo mundo tem... quer dizer, qualquer cidadão que possua um celular tem, na verdade, uma mídia portátil no bolso. Com o celular, qualquer pessoa pode fazer o que a mídia faz também. Então todos os pecados da mídia vieram à tona. Todo mundo tem consciência. Este é o momento para puxarmos o freio de arrumação. Se considerarmos os maiores jornais, aqui de São Paulo, vamos verificar que eles cometem erros diariamente. Se pegarmos uma edição de qualquer jornal para analisá-lo, vamos encontrar coisas escabrosas e que passam despercebidas porque ninguém tem interesse em reclamar. E a grande imprensa não aceita isso. Ela quer continuar sendo como ela sempre foi, toda-poderosa. Mas se você observar - o Chaparro tem até um trabalho sobre isso: "a revolução das fontes" - o jornalismo mudou porque o mundo mudou, as fontes mudaram... e o jornalista quer continuar do mesmo jeito. Há dez anos, nós ditávamos o que nós queríamos que fosse notícia; para virar notícia, você dependia de um jornalista. Hoje isso se inverteu: quem está pautando os fatos são as fontes... e os jornalistas não querem se conscientizar disso.

(Ivan Paganotti) Esses erros mais evidentes da imprensa nos últimos quinze anos talvez abriram espaço para que a sociedade organizada ou lugares específicos isolados do público clamassem por mais controle, por mais censura?

(Sérgio Mattos) É o que está ocorrendo. O que é que ocorreu agora na Confecom [Conferência Nacional de Comunicação]? O que estão buscando? Mas isso ocorre porque não tem legislação específica. As regulamentações que deveriam ter vindo, previstas na Constituição, não vieram. Então, a sociedade está cobrando. Como a censura ocorre hoje? Organiza-se um grupo de mulheres em Brasília e se condena o conteúdo de um programa de TV; aí a emissora tira o programa do ar porque houve a manifestação das mães contra aquilo; vem a Igreja e condena outra coisa, aí a emissora muda novamente. Então, é a sociedade que está ditando os novos valores, se locomovendo e que está dando opinião.

(Ivan Paganotti) Ainda assim, a palavra "censura" não perdeu um pouco do espaço nobre que ela tinha? Nobre em ambos os sentidos, tanto como o "vilão", para jogar tijolo contra ela, mas também como a grande defensora da moralidade, dos bons costumes?

(Sérgio Mattos) A censura é a ferramenta usada para defender os interesses políticos e econômicos do momento. A censura sempre foi usada para isso, para manter o status quo, dos interesses políticos e interesses econômicos. E mais nada. Ela nunca teve a imagem de "boazinha" porque o que é válido hoje ou o que é certo para você pode ser errado para mim. Então é questão de valor. E os valores são construídos pela sociedade ao longo do tempo. Quantas coisas eram consideradas erradas e hoje são aceitas como normais?

(Ivan Paganotti) A longo prazo a censura perde a guerra, então? Porque as palavras que tanto tentam condenar, os atos que ela reprime acabam vingando. Não se podia falar que mulher se divorcia; aí vem divórcio. Não pode falar palavrão...

(Sérgio Mattos) Mulher desquitada, por exemplo. Tinha uma novela, "Malu Mulher", que passava, na década de 1970, só depois das 22 horas, porque falar de mulher desquitada era um horror e a mulher desquitada era discriminada pela sociedade. Quer dizer, nos últimos anos sofremos uma evolução também nos valores. Então, quando os valores mudam, muda também o sentido da censura, muda o sentido de uma porção de coisas. Agora, a censura mesmo, sob meu ponto de vista, ela é de interesse político ou interesse econômico e vai continuar existindo sempre, porque quem estiver no poder vai 
querer manter e ditar as regras do poder, por meio da manipulação da informação para tirar proveitos escusos ou não.

(Mayra Rodrigues Gomes) $\mathbf{E}$ o interesse econômico vai reverter em interesse político, do mesmo jeito. Eu escrevi um artigo (5) sobre o caráter político de toda e qualquer censura. Mesmo que ela seja censura moral: ela atua no sentido de supervisão e controle das ações, dos hábitos, para produzir uma população - para usar o termo do Foucault - “dócil", acomodada a certos parâmetros. Quando pensamos em censura sob esse viés, pensamos, em contrapartida, na censura que é abertamente instrumento de manutenção de certo poder: a censura que coíbe qualquer crítica, como foi o caso do Larry Rohter, qualquer tomada, qualquer desvelamento de falcatruas ou de negócios mal ajambrados, como é o famoso caso do filho do Sarney. É sob essa acepção que atribuímos à censura uma natureza negativa: ela impede que uma verdade venha à tona.

(Ivan Paganotti) É a questão que queria colocar: as formas de censura atuais são disfarçadas por nomenclaturas específicas. Então não é "censura" dos filmes, é "classificação indicativa".

(Sérgio Mattos) Classificação indicativa nunca foi censura; você está apenas dizendo que o veículo deve transmitir um determinado programa ou conteúdo em tal horário, ou então avisar que aquilo não é apropriado para crianças de tal idade. A classificação indicativa não pode ser caracterizada como uma proibição ou censura porque se os pais permitirem, as crianças podem assistir ao programa.

(Ivan Paganotti) Mas a palavra censura voltou agora a ser um inimigo comum. Não dá mais para defender a censura.

(Sérgio Mattos) A censura nunca foi defendida por ninguém de sã consciência, pois ela só interessa àqueles que carregam o espírito arrogante dos ditadores. A censura é um instrumento por meio do qual se pode manipular a realidade e, exatamente por isso, ela deve ser execrada.

(Mayra Rodrigues Gomes) Nós temos as Senhoras Católicas que defendiam a censura na década de 70, que defendiam a censura dos programas e pediam que os órgãos censórios fizessem alguma coisa, de preferência proibissem.

(Sérgio Mattos) Aí estão as questões dos tabus, os tabus e os valores da sociedade num determinado momento e contexto histórico. Por exemplo, quando a família tradicional se sente agredida em seus valores, ela clama para que aquela agressão não venha à tona, não aconteça ali. Quando determinados grupos solicitam que atitudes sejam tomadas em relação aos abusos daqueles programas, nos confrontamos mais uma vez com os valores sociais adotados e considerados como normais na época. $\mathrm{Na}$ verdade, as pessoas não entendem o significado real da palavra censura e o significado real do que venha a ser a classificação indicativa de programas. Esta é a confusão. Quando as pessoas pedem a ação da censura, é porque elas acham que quem tem que resolver os problemas são as pessoas ou os órgãos que lidam com a censura. Após o regime militar a palavra censura ficou tão em voga, foi tão usada para tudo, que todo mundo afirmava que isso "é censura", aquilo "tudo é censura". A própria imprensa tem banalizado o uso da palavra censura. A população, por sua vez, acha que a lei ou o órgão que deve corrigir os abusos, é a censura. É tudo uma questão de educação, de formação ou de falta de informação. Sendo assim, não podemos dizer que as pessoas estão clamando efetivamente por censura, pois na verdade o que elas querem mesmo é que as autoridades tomem providências contra os abusos da mídia...

(Ivan Paganotti) A mídia luta contra a mídia, tentando abolir, controlar, censurar? Há casos como o do Roberto Carlos contra a editora Planeta, na publicação da biografia dele, um caso de mídia versus mídia.

(Sérgio Mattos) Mas tudo isso tem um interesse comercial por trás. O fato de ser proibido, na nossa cultura, significa que você gostaria de ter acesso ao que é proibido. Então o proibido é estimulante. "É proibido isso, então eu quero fazer, eu quero ver, porque é proibido". Lamentavelmente, atitudes individuais de censurar livros por não concordar com o conteúdo deles tem sido uma prática permanente 
em todas as épocas e independe de grupos políticos, religiosos, ideológicos ou econômicos.

(Nara Lya Cabral) Outra questão atual é o controle interno da informação pelas empresas jornalísticas, a crescente concentração midiática das empresas privadas, por um lado, e por outro lado também não se dá para esperar muito das estatais... Parece um dilema complexo, não consigo vislumbrar o que poderia ser uma solução para ter uma independência maior...

(Sérgio Mattos) É uma situação complicada, porque normalmente as empresas têm seus códigos de conduta internos, que eles consideram como padrão. Se você estiver trabalhando naquela empresa, você tem que seguir as normas adotadas. Nas empresas públicas, a gente não pode dizer o que é que pode vir a ocorrer. Mas, de qualquer jeito, você tem que seguir os padrões e as normas do serviço público também. Você não vai poder fazer diferente. Porque atuar diferentemente no veículo público seria divulgar aquilo que os outros não dão, ou seja, o que não é comercial. No entanto, para vislumbrarmos uma independência maior para a mídia, tanto privada como pública, independente da plataforma utilizada, a solução reside na prestação de um serviço de qualidade, na prática de um jornalismo ético e de credibilidade, que tem a busca da verdade como objetivo.

\section{(Nara Lya Cabral) E não é o que geralmente acontece.}

(Sérgio Mattos) Está tudo muito igual, pois os veículos públicos repetem o mesmo padrão dos veículos privados. O que existe na reação das empresas contra a regulamentação é que todo mundo quer autorregulamentação. Quando você se autorregulamenta, significa que o Estado está se omitindo de suas obrigações. Porque compete ao governo regulamentar tudo, ele está aí para isso. Ele regulamenta o que deve ser feito, determinando os limites, fornecendo os parâmetros. Mas aí, quando há uma pressão da mídia num caso específico pela autorregulamentação, e o governo aceita, ele está se omitindo.

\section{Bibliografia:}

GOMES, Mayra Rodrigues; CASADEI, Eliza Bachega. “A dimensão política da censura moral”. Revista Verso e Reverso (Unisinos), vol. 24, n. 56, 2010, pp.57-70.

MATTOS, Sérgio. Censura de guerra: da Criméia ao Golfo Pérsico. Salvador: Sindicato dos Jornalistas Profissionais do Estado da Bahia, 1991.

O controle dos meios de comunicação. Salvador: Edufba, 1996.

. Mídia controlada: a história da censura no Brasil e no mundo. São Paulo: Paulus, 2005.

\section{Notas:}

(1) MATTOS, Sérgio. Mídia controlada: a história da censura no Brasil e no mundo. São Paulo: Paulus, 2005.

(2) Id. Censura de guerra: da Criméia ao Golfo Pérsico. Salvador: Sindicato dos Jornalistas Profissionais do Estado da Bahia, 1991.

(3) Id. O controle dos meios de comunicação. Salvador: Edufba, 1996.

(4) Id. Mídia controlada: a história da censura no Brasil e no mundo. São Paulo: Paulus, 2005.

(5) GOMES, Mayra Rodrigues; CASADEI, Eliza Bachega. “A dimensão política da censura moral”. 
Revista Verso e Reverso (Unisinos), vol. 24, n. 56, 2010, pp.57-70.

\section{Mini Currículo :}

Mayra Rodrigues Gomes é professora titular do Departamento de Jornalismo e Editoração da Escola de Comunicações e Artes e do Programa de Pós-Graduação em Ciências da Comunicação da Universidade de São Paulo. Pesquisadora com bolsa de Produtividade em Pesquisa do CNPq.

Ivan Paganotti é doutorando e mestre em ciências da comunicação pela ECA-USP, sob orientação da Profa. Dra. Mayra Rodrigues Gomes, e jornalista formado pela mesma instituição.

Nara Lya Cabral é estudante de graduação do curso de jornalismo da ECA-USP. É bolsista de iniciação científica da Fapesp sob orientação da Profa. Dra. Mayra Rodrigues Gomes junto ao projeto temático "Comunicação e Censura - análise teórica e documental de processos censórios a partir do Arquivo Miroel Silveira da Biblioteca da ECA-USP", atuando no eixo de pesquisa "Liberdade de Expressão: Manifestações no Jornalismo". 